\title{
A survey on clinicians preferences in reducing postoperative pain in endodontic practice
}

\author{
Hakan Arslan, ${ }^{1}$ Fatih Seçkin, ${ }^{1}$ İsmail Davut Çapar, ${ }^{2}$ \\ Hany Mohamed Aly Ahmed, ${ }^{3}$ Eyüp Candaş Gündoğdu' \\ ${ }^{1}$ Department of Endodontics, Atatürk University Faculty of Dentistry, Erzurum, Turkey \\ ${ }^{2}$ Department of Endodontics, İmir Katip Çelebi University Faculty of Dentistry, İzmir, Turkey \\ ${ }^{3}$ Department of Conservative Dentistry, University Sains Malaysia, School of Dental Sciences, Kelantan, Malaysia
}

\begin{abstract}
Objective: The aim of the present study is to investigate the preferences of general dental practitioners and endodontists in the management of postoperative pain.

Methods: An electronic questionnaire was prepared, and then sent to all members $(n=11253)$ of an internet group (International Association of Endodontic Education, Research and Practice). Chi square test was used for data analysis, and the level of significance was set at 0.05 .

Results: Results showed that $85.5 \%$ of the participants expect postoperative pain and prescribe analgesics in patients with preoperative pain $(p<0.001)$, and $32.8 \%$ of the participants expect postoperative pain and prescribe analgesics in retreatment cases $(p<0.001)$. Expectations of postoperative pain from using the hand files was the highest among other instrumentation techniques, and the difference was statistically significant $(p<0.001)$. The most preferred drug type prescribed by the participants is NSAIDs $(42 \%)(p<0.001)$. More than half of the participants do not prescribe a combination with narcotic for the management of postoperative pain $(p<0.001)$.

Conclusion: In conclusion, postoperative pain remains a frequent suspected sequelae of endodontic procedures, especially in patients with preoperative pain and retreatment cases. The management of postoperative pain and methods for prevention show wide variations. A universal agreement is required to standardize methods to manage and prevent postoperative pain.
\end{abstract}

Keywords: Endodontics; postoperative pain; survey.

$\mathrm{P}$ ain perception is a highly subjective and variable experience modulated by multiple physical and psychological factors, and pain reporting is influenced by factors other than the experimental procedure. ${ }^{[1]}$ One of the most important aspects in root canal treatment is to control the pain. Endodontic postoperative pain is a frequent complication. According to a systematic review, the incidence of postoperative pain ranges from $3 \%$ to as high as $58 \%$ of patients. $^{[2]}$

Investigators examined potential predictors of the level of postoperative pain caused by endodontic procedures. Although age ${ }^{[3]}$ gender, ${ }^{[4]}$ type of tooth, ${ }^{[5]}$ history of allergic reaction, ${ }^{[3]}$ systemic steroid therapy, ${ }^{[5]}$ preoperative swelling, ${ }^{[5]}$ the absence of periapical lesion, ${ }^{[3]}$ and pulp

Correspondence: Dr. Fatih Seçkin. Atatürk Üniversitesi Diş Hekimliği Fakültesi,

Endodonti Anabilim Dalı, Erzurum, Turkey.

Tel: +90 442 - 2960942 e-mail: fatihseckin88@gmail.com

Submitted: April 03, 2016 Accepted: April 26, 2016 
necrosis ${ }^{[6]}$ have been reported as potential predictors for postoperative pain, the presence of preoperative pain and reduced mechanical pain threshold or percussion sensitivity are the main factors in predicting the level of postoperative pain. ${ }^{[3,7-9]}$ However, literature is scarce with regards to factors which general dental practitioners or endodontists consider in predicting postoperative pain.

The management of postoperative pain has been a subject of many research studies including preoperative explanations and instructions, ${ }^{[10]}$ long-acting anesthesia, ${ }^{[11]}$ the glide path. ${ }^{[12]}$ occlusal reduction, ${ }^{[13,14]}$ medication using aspirin, non-steroid anti-inflammatory drugs (NSAIDs), combination of ibuprofen and acetaminophen, ${ }^{[15]}$ narcotic analgesics, ${ }^{[16]}$ combination of narcotic analgesics with aspirin $^{[17]}$ or acetaminophen, ${ }^{[18]}$ or steroidal anti-inflammatory drugs. ${ }^{[19,20]}$

The aim of the present study is to investigate the preferences of the general dental practitioners and endodontists in the management of postoperative pain.

\section{Materials and methods}

An electronic questionnaire was prepared according to Mickel et al. ${ }^{[21]}$ with modification, and then sent to all members $(n=11253)$ of a Facebook group (International Association of Endodontic Education, Research and Practice - https://www.facebook.com/ groups/871341449604944/). The survey consisted of 11 questions as shown in Table 1. Chi square test was used for data analysis, and the level of significance was set at 0.05 .

\section{Results}

268 participants from 6 continents (Asia, Europe, Africa, Australia, North and South America) have responded giving a response rate of $\sim 2 \%$ (Table 1 ).

Results showed that as much as $85.5 \%$ of the participants expect postoperative pain and prescribe analgesics in patients with preoperative pain $(\mathrm{p}<0.001)$.

In terms of the treatment procedure, $32.8 \%$ of the participants expect postoperative pain and prescribe analgesics in retreatment cases $(\mathrm{p}<0.001)$.

Significant differences $(\mathrm{p}<0.001)$ were also detected in the methods used for prevention of the postoperative pain including administration of analgesics immediately after treatment, detailed explanations of the procedures or the expected benefits and the possible pain as well as occlusal reduction.

Interestingly, about $38 \%$ of the participants believe that none of the instrumentation technique (hand/reciprocation/rotary) is responsible for postoperative pain.
However, expectations of postoperative pain from using the hand files was the highest among other instrumentation techniques, and the difference was statistically significant $(\mathrm{p}<0.001)$.

The most preferred drug type prescribed by the participants is NSAIDs $(42 \%)(\mathrm{p}<0.001)$. Notably, about one third of participants recommend taking the medication when needed, and a similar percentage of participants recommend taking the medication for only $\mathbf{l}$ - days. Interestingly, more than half of the participants do not prescribe a combination with narcotic for the management of postoperative pain $(\mathrm{p}<0.001)$.

\section{Discussion}

Several studies have shown that the presence of preoperative pain can significantly increase the probability of postoperative pain..$^{[3,7-9]}$ The current investigation shows that participants would expect postoperative pain, and prescribe analgesics to patients with preoperative pain. Moreover, the participants did not expect postoperative pain and prescribe analgesics to patients with reduced mechanical pain threshold or percussion sensitivity. Similarly, Parirokh et al. ${ }^{[22]}$ mentioned that the presence of moderate-to-severe preoperative pain may be a stronger predictor of postoperative pain than tenderness to percussion.

Participants in this study expect postoperative pain, and prescribe analgesics in retreatment cases. This finding is consistent to one study which showed that retreated cases had a higher incidence of interappointment emergency than those received initial treatments. ${ }^{[3]}$

Detailed explanation of the procedures, expected benefits, and possible pain responses help to allay patients' anxiety and apprehension and reduce tension. ${ }^{[23]}$ The stress can suppress the immune system and reduces the level of circulating antibodies and suppresses the reactivity of lymphocytes to mitogenic and antigenic stimulation. ${ }^{[23]}$ This explains why many of the participants would prefer detailed explanations of the procedures or the expected benefits and the possible pain to prevent postoperative pain.

Data available on the effect of the occlusal reduction on the postoperative pain is contradictory. Rosenberg, Babick $^{[24]}$ found that occlusal reduction prevents postoperative pain in those patients whose teeth initially exhibit pulp vitality, percussion sensitivity, preoperative pain, and/or the absence of periradicular radiolucency. However, Parirokh, Rekabi ${ }^{[22]}$ reported that occlusal surface reduction did not provide any further reduction in the postoperative pain for teeth with irreversible pulpitis and mild tenderness to percussion compared with no occlusal 
Table 1. The survey consisted of 11 questions

Questions

1. On which patient do you usually expect postoperative pain and prescribe analgesics?

2. In which treatment do you usually expect postoperative pain and prescribe analgesics?

3. Which method do you use to prevent postoperative pain?

4. After which instrument do you expect postoperative pain?

5. What do you usually have your patients take postoperatively?

6. How long do you typically recommend your patients take a non-narcotic pain medication postoperatively after endodontic therapy?

\section{Answers}

With preoperative pain

Without sinus tract

With pulp necrosis

Without periapical lesion

With preoperative swelling

With reduced mechanical pain, threshold

or percussion sensitivity

As needed

None of them

Total

Single visit in a vital tooth

Single visit in a necrotic tooth

Calcium hydroxide was placed to the

working length in a vital tooth

Calcium hydroxide was placed to the

working length in a necrotic tooth

Retreatment

Total

Detailed explanations of the procedures, the expected benefits, and the possible pain Long-acting anesthesia

Glide path

Occlusal reduction

Administration of analgesics preoperatively

Administration of analgesics immediately

after treatment

Administration of antihistamines

Low-level laser therapy

Acupuncture

Total

Hand File

Rotary NiTi

Reciprocating instruments

None of them

Total

No medication

Acetaminophen

NSAIDs and Acetaminophen alternatively

NSAIDs

Selective inhibitors of COX-2

Aspirin

Mefenamic acid

Opioids

Combination of opioid and acetaminophen,

aspirin or ibuprofen

Corticosteroids

Total

1-2 days

3-4 days

5-7 days

8-10 days

Other

As needed

Total
Frequency

Percent

230

0

0

0

30

0

0

0

11.2

0

0

$0 \quad 0$

0

260

0

97.0

19.4

19.4

52

18

25

88 
Table 1. The survey consisted of 11 questions (cont.)

7. How many times a day do you have your patients take a non-narcotic pain medication for postoperative pain control?

8. What is your choice of a combination narcotic that you would use to help your patients manage their severe postoperative endodontic pain?

9. Please select one of following that best describes your practice background

10. When did you graduate from the dental faculty?

11. Which location do you live?

\begin{tabular}{|c|c|c|}
\hline $1 \mathrm{X} /$ day & 7 & 2.6 \\
\hline $2 \mathrm{x} /$ day & 76 & 28.4 \\
\hline $3 \mathrm{X} /$ day & 60 & 22.4 \\
\hline $4 \mathrm{X} /$ day & 3 & 1.1 \\
\hline Others & 4 & 1.5 \\
\hline As Needed & 81 & 30.2 \\
\hline Total & 268 & 100.0 \\
\hline No narcotics are prescribed & 142 & 53.0 \\
\hline Hydrocodone and Acetaminophen & 3 & 1.1 \\
\hline Hydrocodone and Aspirin & 0 & 0 \\
\hline Propoxyphene and Acetaminophen & 1 & 4 \\
\hline Codeine and Acetaminophen & 34 & 12.7 \\
\hline Oxycodone and Aspirin & 2 & 7 \\
\hline Narcotic and Ibuprofen & 38 & 14.2 \\
\hline Total & 225 & 84.0 \\
\hline Undergraduate student & 7 & 2.6 \\
\hline Clinician & 91 & 34.0 \\
\hline Postgraduate student (In Endodontics) & 36 & 13.4 \\
\hline Endodontist & 133 & 49.6 \\
\hline Total & 267 & 99.6 \\
\hline Prior to 1980 & 4 & 1.5 \\
\hline Between 1981-1990 & 21 & 7.8 \\
\hline Between 1991-2000 & 51 & 19.0 \\
\hline Between 2001-2015 & 182 & 67.9 \\
\hline Continue & 9 & 3.4 \\
\hline Total & 267 & 99.6 \\
\hline Asia & 116 & 43.3 \\
\hline North America & 26 & 9.7 \\
\hline South America & 40 & 14.9 \\
\hline Europe & 57 & 21.3 \\
\hline Africa & 27 & 10.1 \\
\hline Australia & 1 & 4 \\
\hline Total & 267 & 99.6 \\
\hline
\end{tabular}

reduction. According to results of the present study, occlusal reduction was ranked third among the most preferred to prevent postoperative pain.

The administration of analgesics immediately after treatment was preferred by more than one third of participants to prevent postoperative pain. In previous studies, the use of analgesics were found to be effective in reducing postoperative pain ${ }^{[25,26]}$ Although long-acting anesthesia, ${ }^{[11]}$ administration of analgesics preoperatively ${ }^{[27,28]}$ and glide path ${ }^{[11]}$ have been shown to be effective in reducing postoperative pain, most of participants did not choose these methods.

Results showed that expectations of postoperative pain from using the hand files was the highest among other instrumentation techniques $(\mathrm{p}<0.001)$. One study showed that patients who received root canal treatment using con- ventional step-back technique by using hand files reported a significantly higher incidence of postoperative pain after 2 days compared to ProTaper system in both one- and multiple visits. ${ }^{[29]}$ In studies in which apically extruded debris was evaluated, the hand file resulted in more debris than rotary and reciprocating files. ${ }^{[30,31]}$

According to the present survey, the most preferred drug type by the participants was NSAIDs (42\%). The literature supports the use of NSAIDs for pain relief and control, especially when given immediately preoperatively (grade A). ${ }^{[32]}$ The second most preferred drug type was NSAIDs and acetaminophen alternatively. Menhinick, Gutmann $^{[15]}$ found that a combination of acetaminophen and ibuprofen was more effective than ibuprofen alone in managing postoperative pain. However, their investigation included numerous pulpal conditions that might have 
differing postoperative courses. Wells, Drum ${ }^{[26]}$ compared the effect of ibuprofen versus ibuprofen/acetaminophen combination used for the management of postoperative endodontic pain in symptomatic patients, and found that there was no significant difference between the ibuprofen and ibuprofen/acetaminophen groups for analgesic use or escape medication use.

Jaber, Swaim ${ }^{[33]}$ reported the presence of mu-opioid receptors in the human dental pulp. The use of most opioids, including pentazocine/naloxone, is generally limited by adverse side effects including nausea, emesis, dizziness, drowsiness, respiratory depression, constipation, and neuropsychiatric effects such as hallucinations. Thus, Ryan, Jureidini ${ }^{[16]}$ do not recommend prescribing opioid analgesics alone for the management of postoperative endodontic pain. If needed for severe pain, a combination NSAIDs/opioid formulation is preferred because it permits the use of a lower dose of the opioid, thereby reducing the side effects. According to the survey, the participants did not prefer the narcotics in cases with severe postoperative endodontic pain.

\section{Conclusions}

Postoperative pain remains a frequent suspected sequelae of endodontic procedures, especially in patients with preoperative pain and retreatment cases. The management of postoperative pain and methods for prevention show wide variations. An universal agreement is required to standardize methods to manage and prevent postoperative pain.

Conflict of interest: None declared.

\section{References}

1. Bender IB. Pulpal pain diagnosis-a review. J Endod 2000;26:175-9. Crossref

2. Sathorn C, Parashos P, Messer H. The prevalence of postoperative pain and flare-up in single- and multiple-visit endodontic treatment: a systematic review. Int Endod J 2008;41:91-9.

3. Torabinejad M, Kettering JD, McGraw JC, Cummings RR, Dwyer TG, Tobias TS. Factors associated with endodontic interappointment emergencies of teeth with necrotic pulps. J Endod 1988;14:261-6. Crossref

4. Watkins CA, Logan HL, Kirchner HL. Anticipated and experienced pain associated with endodontic therapy. J Am Dent Assoc 2002;133:45-54. Crossref

5. Glennon JP, Ng YL, Setchell DJ, Gulabivala K. Prevalence of and factors affecting postpreparation pain in patients undergoing two-visit root canal treatment. Int Endod J 2004;37:29-37. Crossref

6. Walton R, Fouad A. Endodontic interappointment flare- ups: a prospective study of incidence and related factors. J Endod 1992;18:172-7. Crossref

7. Morse DR, Koren LZ, Esposito JV, Goldberg JM, Belott RM, Sinai IH, et al. Asymptomatic teeth with necrotic pulps and associated periapical radiolucencies: relationship of flare-ups to endodontic instrumentation, antibiotic usage and stress in three separate practices at three different time periods. Int J Psychosom 1986;33:5-87.

8. Imura N, Zuolo ML. Factors associated with endodontic flare-ups: a prospective study. Int Endod J 1995;28:261-5.

9. Gopikrishna V, Parameswaran A. Effectiveness of prophylactic use of rofecoxib in comparison with ibuprofen on postendodontic pain. J Endod 2003;29:62-4. Crossref

10. Andrew JM. Recovery from surgery, with and without preparatory instruction, for three coping styles. J Pers Soc Psychol 1970;15:223-6. Crossref

11. Parirokh M, Yosefi MH, Nakhaee N, Manochehrifar H, Abbott PV, Reza Forghani F. Effect of bupivacaine on postoperative pain for inferior alveolar nerve block anesthesia after single-visit root canal treatment in teeth with irreversible pulpitis. J Endod 2012;38:1035-9. Crossref

12. Pasqualini D, Mollo L, Scotti N, Cantatore G, Castellucci A, Migliaretti G, et al. Postoperative pain after manual and mechanical glide path: a randomized clinical trial. J Endod 2012;38:32-6. Crossref

13. Parirokh M, Rekabi AR, Ashouri R, Nakhaee N, Abbott PV, Gorjestani H. Effect of occlusal reduction on postoperative pain in teeth with irreversible pulpitis and mild tenderness to percussion. J Endod 2013;39:1-5. Crossref

14. Rosenberg PA, Babick PJ, Schertzer L, Leung A. The effect of occlusal reduction on pain after endodontic instrumentation. J Endod 1998;24:492-6. Crossref

15. Menhinick KA, Gutmann JL, Regan JD, Taylor SE, Buschang $\mathrm{PH}$. The efficacy of pain control following nonsurgical root canal treatment using ibuprofen or a combination of ibuprofen and acetaminophen in a randomized, doubleblind, placebo-controlled study. Int Endod J 2004;37:53141. Crossref

16. Ryan JL, Jureidini B, Hodges JS, Baisden M, Swift JQ, Bowles WR. Gender differences in analgesia for endodontic pain. J Endod 2008;34:552-6. Crossref

17. Morse DR, Furst ML, Koren LZ, Bolanos OR, Esposito JV, Yesilsoy C. Comparison of diflunisal and an aspirin-codeine combination in the management of patients having one-visit endodontic therapy. Clin Ther 1987;9:500-11.

18. Sadeghein A, Shahidi N, Dehpour AR. A comparison of ketorolac tromethamine and acetaminophen codeine in the management of acute apical periodontitis. J Endod 1999;25:257-9. Crossref

19. Mehrvarzfar P, Shababi B, Sayyad R, Fallahdoost A, Kheradpir K. Effect of supraperiosteal injection of dexamethasone on postoperative pain. Aust Endod J 2008;34:25-9.

20. Pochapski MT, Santos FA, de Andrade ED, Sydney GB. 
Effect of pretreatment dexamethasone on postendodontic pain. Oral Surg Oral Med Oral Pathol Oral Radiol Endod 2009;108:790-5. Crossref

21. Mickel AK, Wright AP, Chogle S, Jones JJ, Kantorovich I, Curd F. An analysis of current analgesic preferences for endodontic pain management. J Endod 2006;32:1146-54.

22. Parirokh M, Rekabi AR, Ashouri R, Nakhaee N, Abbott PV, Gorjestani H. Effect of occlusal reduction on postoperative pain in teeth with irreversible pulpitis and mild tenderness to percussion. J Endod 2013;39:1-5. Crossref

23. Seltzer S, Naidorf IJ. Flare-ups in endodontics: II. Therapeutic measures. 1985. J Endod 2004;30:482-8; discussion 475. Crossref

24. Rosenberg PA, Babick PJ, Schertzer L, Leung A. The effect of occlusal reduction on pain after endodontic instrumentation. J Endod 1998;24:492-6. Crossref

25. Mehrvarzfar P, Abbott PV, Saghiri MA, Delvarani A, Asgar K, Lotfi M, et al. Effects of three oral analgesics on postoperative pain following root canal preparation: a controlled clinical trial. Int Endod J 2012;45:76-82.

26. Wells LK, Drum M, Nusstein J, Reader A, Beck M. Efficacy of Ibuprofen and ibuprofen/acetaminophen on postoperative pain in symptomatic patients with a pulpal diagnosis of necrosis. J Endod 2011;37:1608-12. Crossref

27. Arslan H, Topcuoglu HS, Aladag H. Effectiveness of tenoxicam and ibuprofen for pain prevention following endodontic therapy in comparison to placebo: a randomized double-blind clinical trial. J Oral Sci 2011;53:15761. Crossref

28. Attar S, Bowles WR, Baisden MK, Hodges JS, McClanahan SB. Evaluation of pretreatment analgesia and endodontic treatment for postoperative endodontic pain. J Endod 2008;34:652-5. Crossref

29. Ahmed Mustafa BD. Postoperative pain and flare-up in one- and multiple-visits endodontic treatment for pulpally vital molars. Mustansiria Dental Journal 2008;5:348-53.

30. Topçuoğlu G, Topçuoğlu HS, Akpek F. Evaluation of apically extruded debris during root canal preparation in primary molar teeth using three different rotary systems and hand files. Int J Paediatr Dent 2015. Crossref

31. H K S, T S S, Goel BR, T N N, Bhandi SH. Quantitative assessment of apical debris extrusion and intracanal debris in the apical third, using hand instrumentation and three rotary instrumentation systems. J Clin Diagn Res 2014;8:206-10.

32. Sutherland S, Matthews DC. Emergency management of acute apical periodontitis in the permanent dentition: a systematic review of the literature. J Can Dent Assoc 2003;69:160.

33. Jaber L, Swaim WD, Dionne RA. Immunohistochemical localization of mu-opioid receptors in human dental pulp. J Endod 2003;29:108-10, Crossref 